Available online on 15.01.2021 at http://ujpr.org
Universal Journal of Pharmaceutical Research
An International Peer Reviewed Journal
Open access to Pharmaceutical research

\title{
PREPARATION AND CHARACTERIZATION OF THYMOQUINONE NANOPARTICLES PEGYLATED AS DRUG DELIVERY SYSTEM A. Hasrawati ${ }^{*}{ }^{*}$, Irsan Rizaldi ${ }^{2}{ }^{\circ}$, Neneng Amelia Bakri² ${ }^{\circledR}$, Deisy Febrianti ${ }^{2}{ }^{\circ}$, A Mumtihanah Mursyid ${ }^{1}$ \\ ${ }^{I}$ Pharmaceutical Department, Faculty of Pharmacy, Universitas Muslim, Indonesia. ${ }^{2}$ Faculty of Pharmacy, Universitas Muslim, Indonesia.
}

\section{ABSTRACT}

Objective: Thymoquinone is a main component of Black Cumin (Nigella sativa Linn.) with various pharmacological activities, but has poor stability and bioavailability. The purpose of this study was to carry out the preparation and characterization of timoquinone nanoparticles PEGylation.

Methods: The Thymoquinone nanoparticles (TQ-NP) were made with PEGylation using PEG 6000 with the concentrations on each preparation of $3 \mathrm{mM}(\mathrm{A}), 4 \mathrm{mM}(\mathrm{B})$, and $5 \mathrm{mM}(\mathrm{C})$ then were evaluated by the parameter of yield percentage Entrapment Efficiency (EE) and Drug Loading (DL), drug release, size and distribution particle, morphological analysis and Fourier Transform-Infrared spectrophotometer (FTIR).

Results: Thymoquinone nanoparticle was PEGylated with PEG 6000 has the highest efficiency entrapment of $99.9718 \pm 0.029 \%$ in formula A, with the capacity of drug loading $0,66 \%$. Formulation A release $99.9718 \pm 0.029 \%$ of Thymoquinone at 50 minutes. The morphological observations with Scanning Electron Microscope (SEM) showed spherical nanoparticles morphology.

Keywords: Black Cumin, Nanoparticles, PEG 6000, Pegylation, Thymoquinone.

Article Info: Received 11 September 2020; Revised 5 December; Accepted 3 January, Available online 15 January 2021

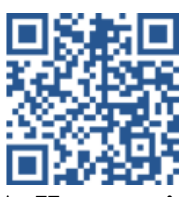
Cite this article-

Hasrawati A, Rizaldi I, Bakri NA, Febrianti D, Mursyid AM. Preparation and characterization of thymoquinone nanoparticles PEGylated as drug delivery system. Universal Journal of Pharmaceutical Research 2020; 5(6):13-17.

DOI: https://doi.org/10.22270/ujpr.v5i6.506

Address for Correspondence

A. Hasrawati, Pharmaceutical Department, Faculty of Pharmacy, Universitas Muslim, Indonesia, E-mail: a.hasrawati@umi.ac.id

\section{INTRODUCTION}

Black cumin mostly used as a food additive and has properties to treat several diseases due to its various chemical properties ${ }^{1}$. Black cumin oil has various therapeutic benefits such as dysentery, headaches ${ }^{1}$, gastrointestinal problems ${ }^{2,3}$, eczema, hypertension ${ }^{4}$, and obesity, etc. Thymoquinone (TQ) is one of the major active chemical component of black cumin oil (Nigella sativa Linn) ${ }^{5}$. TQ can increase the immune system of patients with bronchial asthma due to allergies, and the main properties as an antiinflammatory ${ }^{1,6}$ and antioxidants. In a study conducted by Salim et al., showed that TQ has an IC value of 1.5 $\pm 0.04 \mu \mathrm{g} / \mathrm{mL}^{7}$. Thymoquinone as an anti-inflammatory works by inhibiting the cyclooxygenase (COX) and lipoxygenase (LO) pathways ${ }^{6}$. In addition, black cumin oil also contains chemical components such as, nigellienine, nigellamine-n-oxide, essential oils, fatty oils, alkaloid group compounds, saponins, steroids, isokuinolin alkaloids, oleats, and linolenate ${ }^{8}$. Thymoquinone is an essential oil that has volatile properties, low melting point and is easily oxidized, so it will be difficult to formulate into a pharmaceutical dosage form ${ }^{9}$. In addition, thymoquinone is also difficult to dissolve in water, and has a poor bioavailability $^{10}$. To overcome this problem a nanoparticle preparation was developed as a thymoquinone carrier ${ }^{11}$. Nanoparticles are colloidal particles that range in size from $1-100 \mathrm{~nm}$. The drug is dissolved, adsorbed, encapsulated or attached to the nanoparticle matrix ${ }^{12}$. The advantage of nanoparticles is that it increases the bioavailability of the drug, small doses, reduces side effects, increases the surface area to produce rapid solubility of active ingredients in the fluid environment, such as in the digestive tract ${ }^{13}$. If the dissolution rate is high, the absorption and bioavailability of the drug will also be better ${ }^{14}$. Within a few years, many methods have been designed in the development of formulations to improve the characteristic and pharmacokinetics properties of a drug compound to produce the maximum benefit of therapeutic action ${ }^{12}$. One of them is PEGylated nanoparticles. 
Pegylation is a modification of protein, peptide and non peptide molecules by forming bonds or links with one or more chains of polyethylene glycol (PEG). Polyethylene glycol (PEG) is a polymer that has been approved by the FDA in the application of nanomedicine and biomedicine. A good nanoparticle formulation should have a high drug loading capacity ${ }^{15}$.
The molecular weight of polyethylene glycol (PEG) used can affect the loading capacity of the drug so that it is necessary to optimize the type and concentration of PEG used based on its molecular weight ${ }^{16}$. Based on this, it is necessary to do research on the preparation and characterization of thymoquinone nanoparticles so that they can be used for drug delivery.

Table 1: Thymoquinone nanoparticles optimization.

\begin{tabular}{lcccc}
\hline Materials & \multicolumn{3}{c}{ Concentrations } & $\begin{array}{c}\text { Formed Solid } \\
\text { Particles }\end{array}$ \\
\hline & P A & P B & P C & \\
\hline Thymoquinone & $1 \mathrm{mg}$ & $1 \mathrm{mg}$ & $1 \mathrm{mg}$ & - \\
PEG 400 & $72 \mathrm{mg}$ & - & - & No \\
PEG 4000 & - & $72 \mathrm{mg}$ & - & No \\
PEG 6000 & - & - & $72 \mathrm{mg}$ & Yes \\
Tween 80 & $0.03 \mathrm{ml}$ & $0.03 \mathrm{ml}$ & $0.03 \mathrm{ml}$ & - \\
Ethanol & Ad 5 ml & Ad 5 ml & Ad 5 ml & - \\
\hline
\end{tabular}

\section{SUBJECTS AND METHODS}

Thymoquinone (TQ) was obtained from Sigma Aldrich USA. The TQ was prepared TQ was prepare into the form nanoparticles PEGylated. In this study, the TQ was quantified using spectrophotometer UV-Vis.

\section{Standard Solution preparation}

A stock solution of $100 \mathrm{ppm}$ of Thymoquinone concentration was made by weighing $10 \mathrm{mg}$ of TQ and dissolving it in $100 \mathrm{~mL}$ of phosphate buffer $\mathrm{pH} \mathrm{7.4.}$ The solution is used to determine the maximum wavelength of TQ. The $\lambda_{\max }$ was observed with a spectrophotometer UV-VIS at 200-400 nm.

Preparation of Thymoquinone Nanoparticle (TQNP)

Nanoparticles are made by the pegylation method. A series of concentrations of PEG 400, PEG 4000 and PEG 6000 were made as polymers, Tween 80 as a surfactant in the optimization of nanoparticles can be seen in Table 1. Each formula was made as much as 5 $\mathrm{mL}$ with $1 \mathrm{mg}$ of TQ. Dissolved $1 \mathrm{mg}$ of TQ in $70 \%$ ethanol. Tween 80 added $0.03 \mathrm{~mL}$ into the mixture until it was homogeneous, then the mixture was slowly dripped into polyethylene glycol (PEG) while being stirrer at a speed of $700 \mathrm{rpm}$ for 6 hours. The TQ-PEG dispersion was then evaporated to remove solvents and made into powder with freeze drying technique to obtain TQ-NP PEGylated ${ }^{5}$.

\section{Characterization of TQ-NP \\ TQ-NP Morphology}

Morphological observations of TQ-NP were carried out using Scanning Electron Microscope (SEM). The TQNP were dropped over cooper gird then coated with an auto carbon coated (JOEL JEM, Japan) tool for 5 seconds, dried at room temperature for 24 hours. TQ$\mathrm{NP}$ was analyzed by accelerating the voltage at $120 \mathrm{kV}$ and magnification of 60,000 .

\section{Particle Size}

TQ-NP particle size was determined using a NicompTM 380 ZLS Submicron particle size analyzer. A total of 2 drops of $\mathrm{pH} 4.0$ TQ-NP added $5.0 \mathrm{~mL}$ aquadestillata, then mixed by flipping through a conical tube. After that, $3.0 \mathrm{~mL}$ was taken and put into cuvettes to analyze distribution and particle size.

\section{The Entrapment Efficiency (EE)and The Loading Drug}

$5 \mathrm{mg}$ of TQ-NP were centrifuged at room temperature with $15.000 \mathrm{rpm}$ a, for 30 minutes and then absorbance was measured with UV-Vis spectrophotometry. Entrapment Efficiency of TQ-NP was calculated by the equation:

$$
\% \mathrm{EE}=\frac{\text { drug Total }- \text { Free drug }}{\text { Drug Total }} \times 100
$$

\section{Drug Release Study}

The release of TQ-NP carried out in vitro using Franz diffusion cells, the membrane used was removable python morolus skin. The medium fluid in the receptor compartment used was a phosphate buffer $\mathrm{pH}$ of 7.4 and maintained at a temperature of $35 \pm 0.5^{\circ} \mathrm{C}$ as much as $50 \mathrm{~mL}$. The snake skin is then placed between donor compartments with receptor compartments, samples weighed as much as $5 \mathrm{mg}$ are applied to the surface of the skin. Medium liquid is flowed through the bottom of the skin membrane with the help of a magnetic stirrer at a speed of $100 \mathrm{rpm}$. Sampling was carried out at the $10,20,30,40,50,60,70,80,90,110$, and 120 minute where $5 \mathrm{~mL}$ samples were taken from the receptor compartment using a syringe and immediately replaced with a $5 \mathrm{~mL}$ medium solution. The samples were then measured for absorbance using UV-Vis spectrophotometry at a maximum wavelength of 260 $\mathrm{nm}$.

\section{RESULTS AND DISCUSSION}

The development of nanoparticles using thymoquinone as an active ingredient is based on volatility, low melting point and easily oxidized ${ }^{10}$. Thymoquinone is also difficult to dissolve in water, so it has a small bioavailability". Therefore, thymoquinone is made in the form of nanoparticles to improve the bioavailability of drugs, improve the physical properties of chemicals ${ }^{10}$ and protect medicinal ingredients so as to provide an effective therapeutic effect ${ }^{17}$. In this study, the resulting nanoparticle TQ-NP was characterized by evaluating nanoparticle morphology, size and distribution of particles, measurement of entrapment efficiency (EE) and drug loading (DL), and 
nanoparticle release. In this study thymoquinone was prepared to form nanoparticles with PEGylated method using PEG 6000 as a polymer. PEG was chosen as a polymer used because it was 'safe' in the body and approved for use as excipients in many pharmaceutical formulations ${ }^{16}$. PEG has been widely used in various nanoparticle systems to increase surface hydrophilicity and half-life by interacting with blood and mononuclear phagocyte cell systems. Pegylation is formed because physical adsorption or covalent grafting results in a layer of PEG on the surface of the particles so that it can increase the stability of the medicinal material ${ }^{17}$.

Table 2: Entrapment efficiency (EE) of TQ-NP.

\begin{tabular}{lc}
\hline $\begin{array}{l}\text { Preparations } \\
\text { (TQ:PEG 6000) }\end{array}$ & \% EE \\
\hline A $(1: 3)$ & $99.9718 \pm 0.029$ \\
B $(1: 3)$ & $99.9628 \pm 0.026$ \\
C $(1: 3)$ & $99.9363 \pm 0.049$ \\
\hline
\end{tabular}

To improve the properties of a drug that has poor bioavailability and its solubility can be made into a form of nanoparticles. Some studies have shown both the shape of the PEG configuration and its molecular weight affects the pharmacokinetic properties and biological activity of the drug. It is very important to choose PEG with different molecular weights ${ }^{18}$. In this study used PEG with different molecular weights are PEG 400, PEG 4000, and PEG 6000 and loading with $3 \mathrm{mM}$ of TQ. The Optimization was done by making preparations with a comparison of PEG polymers with different molecular weights, the type of PEG used $(400,4000,6000)$ with a concentration of $3 \mathrm{mM}$.

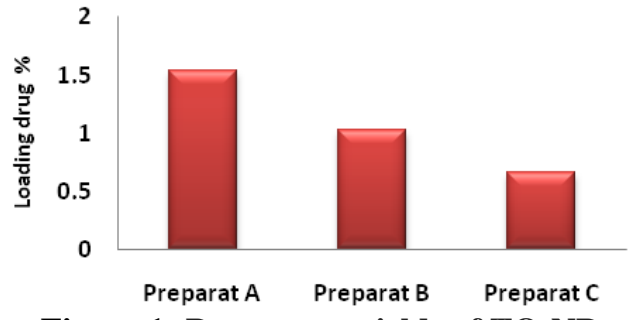

Figure 1: Percentage yields of TQ-NP.

In making the pegylation method thymoquinone and PEG were dissolved in $70 \%$ ethanol, then tween 80 was added as a surfactant as much as $0.03 \mathrm{~mL}$, the distrer was at $700 \mathrm{rpm}$, dropped thymoquinone and distrerer dispersion for 6 hours, using a rotary evaporator at $40^{\circ} \mathrm{C}$ at a speed $50 \mathrm{rpm}$ and mixed with freeze drying technique to form thymoquione nanoparticles.

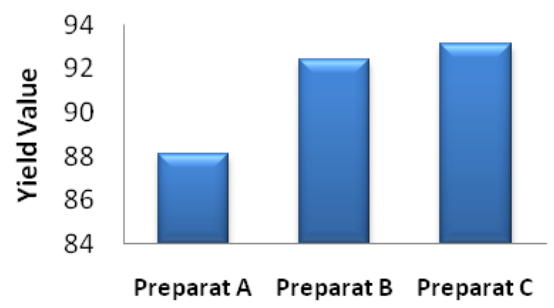

Figure 2: Drug Loading (DL) Histogram of Thymoquinone nanoparticles.

The optimization parameter is to see the formation of particles after being pollinated by the technique of freeze drying.
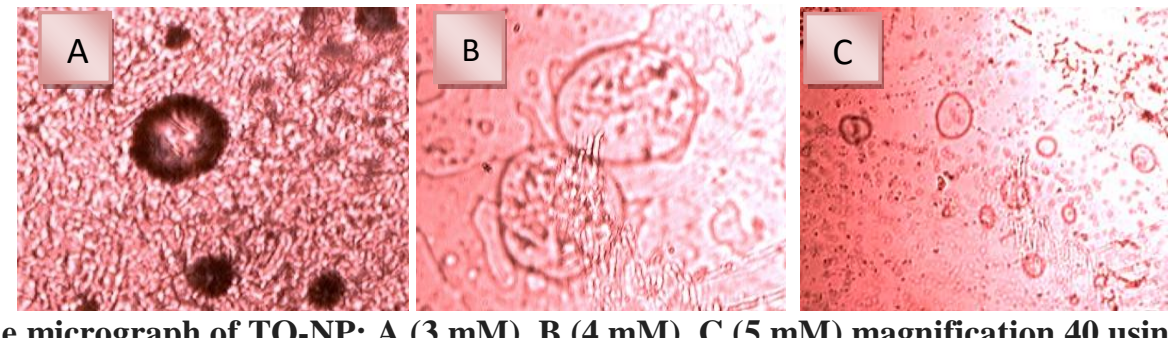

Figure 3: The micrograph of TQ-NP: A $(3 \mathrm{mM})$, B $(4 \mathrm{mM}), \mathrm{C}(5 \mathrm{mM})$ magnification 40 using an irmecoß microscope.

\section{The Efficiency of Entrapment (EE) and the Loading} of Drug (LD)

The Efficiency of Entrapment (EE) shows the ability of polymers to entrapment drugs, while DL shows the ability of drugs to be absorbed into the polymer matrix. EE can be influenced by the concentration of the polymer used in making nanoparticles ${ }^{19}$. The EE test results show that all preparations have\% $\mathrm{EE}$, which are $99.9718 \pm 0.029 \%, \quad 99.9628 \pm 0.026 \%$, and $99.9363 \pm$ $0.049 \%$, respectively. From the results above it can be seen that the higher the polymer concentration will cause the EE value to be low. This can be caused by the high concentration of polymers that will produce a solution with high viscosity so that the drug ingredients will be difficult to diffuse into the polymer matrix ${ }^{18}$. Research conducted by Odeh et al., ${ }^{20}$ who conducted a study of the efficiency of loading timoquinone in liposomes showed a $90 \%$ absorption efficiency of timoquinone and the use of Triton X-100 showed that only $49.6 \%$ of the drug was absorbed, the value was smaller than the results of research that has been done.

The results of the DL test showed that the preparations A (3 mM), B (4 mM), and (5 mM) were $1.54 \%, 1.02 \%$, and $0.66 \%$ respectively. From these results it is known that preparation $\mathrm{A}$ has a high DL value compared to preparations B and C. An ideal nanoparticulate system has a high drug loading capacity thereby reducing the material used for drug delivery ${ }^{18}$. Drug and drug loading is very dependent on drug solubility in materials or polymers ${ }^{22}$, polymer composition, polymer molecular weight, and drug and polymer interactions ${ }^{23}$. Particles Size

Particle size is very important characteristics in nanoparticle systems. The particle size will determine 
the drug distribution in vivo, the fate of the drug in the biological system and its toxicity and the ability to target drugs in the nanoparticle system ${ }^{24}$. The size and distribution of particle also affects drug absorption, drug release and stability of the nanoparticles ${ }^{16}$. The main application of nanoparticles is drug release and drug targeting. It has been found that particle size affects drug release. Small particles produce a larger surface area. As a result, most drugs that are inserted will spread to the surface of the particles to facilitate drug release faster. Instead, the drug will experience slower diffusion in larger ${ }^{24}$. Measurement of size and distribution of nanoparticles using preparations that have good percent EE and in vitro release values. The results showed that preparation $\mathrm{A}$ had an average particle size of $10 \mathrm{~nm}$, which is in the range of size of the nanoparticles $(10-100 \mathrm{~nm})$.
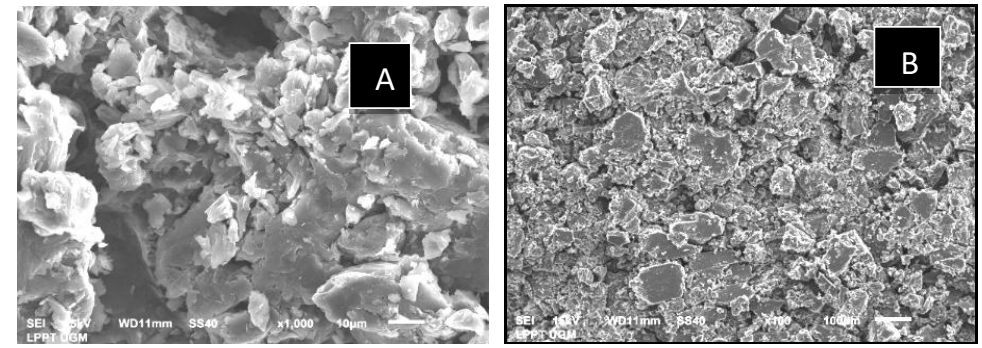

Figure 4: Morphology of thymoquinone nanoparticles using Scanning Electron Microscopy (SEM) with A (1000x magnification) and $B$ (100x magnification).

The Polydispersity Index is a parameter to determine the particle size distribution of nanoparticles with a range that can be absorbed by the PEG 6000 polymer matrix. Preparations A ( $3 \mathrm{mM})$ have IP> 0.5 which is 0.350. According to Avadi in 2010, particles with IP> 0.7 have a very wide size distribution. The smaller IP, shows the particle size is uniform. So that it can be concluded that thymoquinone nanoparticles formed monodispersion or relatively homogeneous.

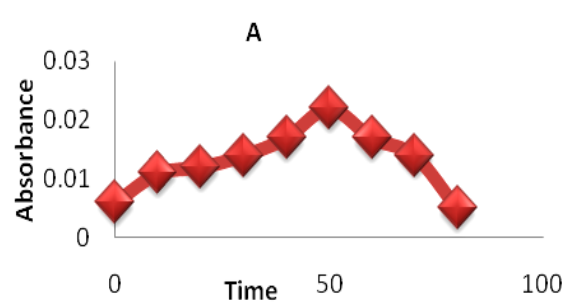

Figure 5: In-vitro release curve for preparation A with a concentration of $3 \mathrm{mM}$.

\section{$T Q-N P$ Morphology}

The morphology of Thymoquinone nanoparticles aims to see the shape and morphology of the nanoparticles formed using the irmeco® microscope and Scanning Electron Microscopy (SEM). Based on the results of observations using the irmeco® microscope shown in Figure 1, the thymoquinone nanoparticles formed have a round shape. Scanning Electron Microscope (SEM) is a type of electron microscope that provides a picture of the surface of a sample by scanning using a highenergy electron beam. Electrons interact with sampleforming atoms that produce signals containing information about the surface topography of the sample. Observations using SEM can be seen in Figure 4. The results of observations on preparations A with a concentration of $3 \mathrm{mM}$ showed a spherical shape on the surface of the particles.

TQ-NP in vitro study

To develop a nanoparticulate system, biodegradation of polymers and the ability of drugs to release from the system are important considerations ${ }^{16}$. In general, the level of drug release depends on: 1 . drug solubility ${ }^{15} ; 2$. surface desorption from adsorbed/ bound drugs; 3 . drug diffusion through the nanoparticle matrix ${ }^{24}$. The erosion /degradation of the nanoparticle matrix and 5 . the combination of the erosion/diffusion process ${ }^{21}$. Solubility, diffusion and biodegradation of matrix materials regulate the release process ${ }^{18}$.

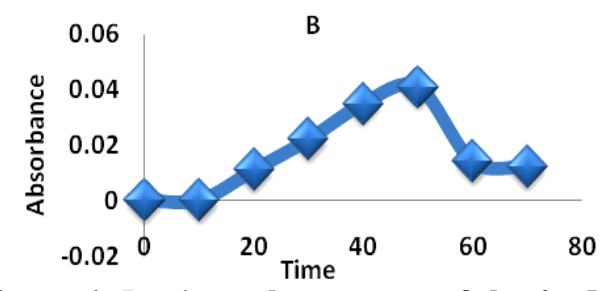

Figure 6: In-vitro release curve of the $4 \mathrm{mM} \mathrm{B}$ preparations.

The nanoparticle diffusion release test was carried out using a Franz diffusion cell with phosphate buffer $\mathrm{pH}$ 7.4 solution. The medium given describes the system of blood flow under the skin. From the results of Thymoquinone release from nanoparticles diffusion can be seen in the figure.

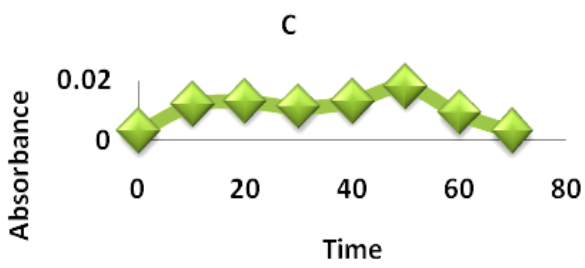

Figure 7: In-vitro release curve for $\mathrm{C}$ preparations with a concentration of $5 \mathrm{mM}$.

The release of the drug can be caused by the presence of drugs that are on the surface of the nanoparticles. The results of the studies in Figure 7, Figure 8, and Figure 9 showed that the highest drug release occurred after 50 minute and no release at 90 minutes, from the release of preparation $\mathrm{A}$ had a longer release time than preparations B and C (Figure 4 and Figure 5). 
In-vitro release graphics for $\mathrm{C}$ preparations with a concentration of $5 \mathrm{Mm}$. The results showed that in Figure 4 and Figure 5, the highest drug release occurred in the $50^{\text {th }}$ minute and no release occurred in the $70^{\text {th }}$ minute.

\section{CONCLUSION}

Thymoquinone has been prepared into nanoparticles PEGylated using polyethylene glycols 6000 at a concentration of $3 \mathrm{mM}, 4 \mathrm{mM}$, and $5 \mathrm{mM}$. Based on the characterization of the entrapment efficiency of nanoparticles obtained the highest adsorption efficiency contained in preparations A $99.9718 \pm 0.029$, and preparations B and C respectively $99.9628 \pm 0.026$, and $99.9363 \pm 0.049$.

\section{AUTHOR'S CONTRIBUTION}

All authors have worked equally for the literature survey, lab work and writing of the manuscript.

\section{CONFLICT OF INTEREST}

No conflict of interest, associated with this work.

\section{ACKNOWLEDGEMENTS}

The authors would like acknowledge Indonesian Ministry of education and Culutre, and faculty of Pharmacy, Universitas Muslim Indonesia.

\section{REFERENCES}

1. Al-Ghamdi MS. Anti-inflammatory, analgesic and antipyretic activity of Nigella sativa. J Ethnopharmacol. 2001; 76: 45-8. https://doi.org/10.1016/s0378-8741(01)00216-1

2. Shakeri F, Zahra G, Bruno M, Ramin M, Mohammad HB. Gastrointestinal effects of Nigella sativa and its main constituent, thymoquinone: a review. Avicenna J Phytomed. 2016; 6(1): 9-20. PMID: 27247918

3. Al mohle IA, Abdulqoder AA, Jabir SM, et al. Gastroprotective effect of an aqueous suspension of black cumin Nigella sativa on necrotizing agents-induced gastric injury in experimental animals. The Saudi J Gastr 2008; 14(3): 128-134. https://dx.doi.org/10.4103\%2F1319-3767.41731

4. Jaarin K, Wai DF, Min HY, et al. Mechanisms of the antihypertensive effects of Nigella sativa oil in L-NAMEinduced hypertensive rats. Clinics (Sao Paulo) 2015; 7(11): $751-757$.

https://dx.doi.org/10.6061\%2Fclinics\%2F2015(11)07

5. Bhattacharya S, Manisha A, Prasun P, et al. PEGylatedthymoquinone-nanoparticle mediated retardation of breast cancer cell migration by deregulation of cytoskeletal actin polymerization through miR-34a. Biomat 2015; 51: 91-107. https://doi.org/10.1016/j.biomaterials.2015.01.007

6. El Gazzar M, El Mezayen R, Marecki JC, et al. Antiinflammatory effect of thymoquinone in a mouse model of allergic lung inflammation. Int Immunopharmacol 2006; 6(7): 1135-1142.

https://doi.org/10.1016/j.intimp.2006.02.004

7. Salim LZA, Mohan S, Othman R, et al. Thymoquinone induces mitochondria-mediated apoptosis in acute lymphoblastic leukaemia in vitro. Molecules 2013; 18(9), 11219-11240. https://doi.org/10.3390/molecules 180911219
8. Khan MA, Afzal M. Chemical composition of Nigella sativa Linn: Part 2 recent advances. Inflammo Pharmacol 2016; 24(2-3), 67-79. https://doi.org/10.1007/s10787-0160262-7

9. Salmani JMM, Asghar S, Lv H, Zhou J. Aqueous solubility and degradation kinetics of the phytochemical anticancer thymoquinone; probing the effects of solvents, $\mathrm{pH}$ and light. Molecules 2014; 19(5): 5925-5939. https://doi.org/10.3390/molecules 19055925

10. Vignesh KS, Renuka DP, Hemananthan E. In vitro studies to analyze the stability and bioavailability of thymoquinone encapsulated in the developed nanocarrier 2019. J Disp Sci Tech; 2020; 41(2).

https://doi.org/10.1080/01932691.2018.1564672

11. Tubesha Z, Bakar ZA, Ismail M. Characterization and stability evaluation of thymoquinone nanoemulsions prepared by high-pressure homogenization. J Nanomat 2013: 126. https://doi.org/10.1155/2013/453290

12. Singh R, Lillard JW. Nanoparticle-based target drug delivery. Exp Mol Pathol 2009; 86: 215-223. https://doi.org/10.1016/j.yexmp.2008.12.004

13. Ballout F, Zeina H, Omar NR, Maamoun F, Hala GM. Thymoquinone-based nanotechnology for cancer therapy: promises and challenges. Drug Disc Today 2018: 23 (5): 1089-1098. https://doi.org/10.1016/j.drudis.2018.01.043

14. Alam S. Khan ZI, Mustafa G, et al. Development and evaluation of thymoquinone-encapsulated chitosan nanoparticles for nose-to-brain targeting: A pharmacoscintigraphic study. Int J Nanomed 2012; 7: 5705-5718. https://doi.org/10.2147/ijn.s35329

15. Pal SL, Jana U, Manna PK, Mohanta GP, Manavalan R. Nanoparticle: An overview of preparation and characterization. J App Pharm Sci 2011; 01 (06): 228-234.

16. Hansen M, Smith MC, Crist RM, Clogston JD, McNeil SE. Analyzing the influence of PEG molecular weight on the separation of PEGylated gold nanoparticles by asymmetricflow field-flow fractionation. Analyt Bioanalyt Chem 2015; 407(29). https://doi.org/10.1007/s00216-015-9056-9

17. Elsaied EH, Dawaba HM, Ibrahim ESA, Afouna MI. Effect of pegylated edge activator on Span 60 based nanovesicles: comparison between Myrj 52 and Myrj 59. Universal J Pharm Res 2019; 4(4):1-8. https://doi.org/10.22270/ujpr.v4i4.290

18. Agrawal P. Significance of Polymers in Drug Delivery System. J Pharmacovigil 2014; 3(1): 1-2. https://doi.org/10.4172/2329-6887.1000e127

19. Tubesha Z, Bakar ZA, Ismail M. Characterization and stability evaluation of thymoquinone nanoemulsions prepared by high-pressure homogenization. J Nanomat 2013: 126. https://doi.org/10.1155/2013/453290

20. Odeh F, Ismail SI, Abu-Dahab R, et al. Thymoquinone in liposomes: a study of loading efficiency and biological activity towards breast cancer. Drug Deliv 2012; 19(8): 371-377. https://doi.org/10.3109/10717544.2012.727500

21. Suka JS, Qingguo X, Namho K, Justin H, Laura ME. PEGylation as a strategy for improving nanoparticle-based drug and gene delivery. Adv Drug Deliv Rev 2016. https://doi.org/10.1016/j.addr.2015.09.012

22. Kumar SKV, Ponnuswamy RD, Saru H, Eswaran H. Synthesis and characterisation of PEG modified chitosan nanocapsules loaded with thymoquinone. IET Biotech 2017; 11 (1):104-112.

https://doi.org/10.1049/iet-nbt.2016.0055

23. Hamidi M, Amir A, Pedram R. Pharmacokinetic Consequences of Pegylation 2008; 13: 399-409. https://doi.org/10.1080/10717540600814402

24. Clogston JD, Patri AK. Zeta potential measurement. In Characterization of nanoparticles intended for drug delivery (63-70). Humana Press 2011.

https://doi.org/10.1007/978-1-60327-198-1_6 